\title{
The FaRE1 LTR-retrotransposon Based SSAP Markers Reveal Genetic Polymorphism of Strawberry (Fragaria $x$ ananassa) Cultivars
}

\author{
Nataliya V. Melnikova ${ }^{1,2}$, Anna V. Kudryavtseva ${ }^{1}$, Anna S. Speranskaya ${ }^{1,3}$, Anastasiya A. Krinitsina ${ }^{3}$, Alexey A. \\ Dmitriev $^{1}$, Maxim S. Belenikin ${ }^{1}$, Vladimir P. Upelniek ${ }^{2}$, Elena R. Batrak ${ }^{4}$, Irina S. Kovaleva ${ }^{4} \&$ \\ Alexander M. Kudryavtsev ${ }^{2}$ \\ ${ }^{1}$ Engelhardt Institute of Molecular Biology, Russian Academy of Sciences, Russia \\ ${ }^{2}$ Vavilov Institute of General Genetics Russian Academy of Sciences, Russia \\ ${ }^{3}$ Lomonosov Moscow State University, Russia \\ ${ }^{4}$ Russian State Agrarian University-MTAA named after K. A. Timiryazev, Russia \\ Correspondence: Nataliya V. Melnikova, Engelhardt Institute of Molecular Biology, Russian Academy of \\ Sciences, Vavilov st. 32, Moscow 119991, Russia. Tel: 7-499-135-2391. E-mail: mnv-4529264@yandex.ru
}

Received: July 8, 2012 Accepted: July 26, 2012 Online Published: October 12, 2012

doi:10.5539/jas.v4n11p111 URL: http://dx.doi.org/10.5539/jas.v4n11p111

\begin{abstract}
The genetic diversity of strawberry $F$. x ananassa varieties with respect to FaRE1 LTR retrotransposon integration sites was studied for the first time. The SSAP method with a single combination of primers revealed 35 polymorphic sites of FaRE1 LTR retrotransposon integration in the strawberry genome. Most of the studied varieties (36 out of 46) had unique combinations of polymorphic FaRE1 insertions but 5 pairs of varieties did not differ in their SSAP markers. Assessment of genetic similarity of strawberry varieties using SSAP markers did not reveal distinct genetic clusters, which may be explained by a relatively short history of selection of this cultivar and by crossing within the same genetic pool.
\end{abstract}

Keywords: Fragaria $\mathrm{x}$ ananassa, SSAP, molecular markers, genetic diversity, LTR-retrotransposons

\section{Introducation}

The strawberry (Fragaria $x$ ananassa Duch.) is the most common small-fruit crop that is cultivated under various agroclimatic conditions. $F . x$ ananassa is an octoploid $(2 \mathrm{n}=8 \mathrm{x}=56)$ originally produced by crossing of the octoploid species $F$. chiloensis and $F$. virginiana, and has a genome AAA'A'BBB'B' comprising four different subgenomes: A, A', B, and B' (Bringhurst \& Gill, 1990). The crossing of $F$. chiloensis and $F$. virginiana took place about 300 years ago, which makes $F$. x ananassa a "young" crop (Hancock, 1999); however, active selection has resulted in hundreds of existing varieties (Faedi et al., 2002).

There is vast literature devoted to the studies of diversity of strawberry and other Fragaria species using different molecular marker systems. The use of protein and DNA-based markers in the studies of strawberries was described in detail by Hokanson and Maas (Hokanson \& Maas, 2001). Molecular genetic research of Fragaria species was carried out using such marker systems as SSR (Simple Sequence Repeats) (Njuguna, 2010), RAPD (Randomly Amplified Polymorphic DNA) (Garcia et al., 2002), RFLP (Restriction Fragment Length Polymorphism) (Vilanova et al., 2008), and AFLP (Amplified Fragment Length Polymorphism) (Lerceteau-Köhler et al., 2003; Tyrka et al., 2002). The strawberry genome was mapped using ISSR (Inter Simple Sequence Repeats) markers (Hussein et al., 2008). One more system of genetic markers used in the study of strawberries was CAPS (Cleaved Amplified Polymorphic Sequences) (Kunihisa et al., 2005).

Another efficient genetic marker system, based on polymorphism of retrotransposon integration sites, holds some advantages over the systems mentioned above. Retrotransposons are mobile genetic elements which undergo reverse transcription (RNA $\rightarrow$ DNA) during replication, after which the new copies are integrated into the genome. Retrotransposons represent a significant component of the plant genome and may constitute over 50\% of the nuclear DNA (Wicker et al., 2009; Pearce et al., 1996; SanMiguel \& Bennetzen, 1998; Meyers et al., 2001). Owing to the ubiquity of these mobile elements in various plant species, their integration activity, the conservative structure of their sequences, and a large number of copies in the euchromatic chromosome regions, they can be used to study genetic diversity in plants and create genetic markers (Feschotte et al., 2002; Kalendar 
et al., 2011). Molecular markers based on polymorphism of retrotransposon integration sites are widely used in assessment of retrotransposon activity, phylogenetic studies, gene mapping, studies of somaclonal variation, and estimation of genetic diversity of cereals (Waugh et al., 1997; Queen et al., 2004; Konovalov et al., 2010), legumes (Ellis et al., 1998; Pearce et al., 2000; Vershinin et al., 2003; Sanz et al., 2007), potato (Lightbourn et al., 2007), vine (Labra et al., 2004), sunflower (Tang et al., 2004), flax (Smykal et al., 2011), and many other plants (Feschotte et al., 2002; Kalendar et al., 2011).

Polymorphism of retrotransposon integration sites in the genome can be revealed by several approaches: IRAP (Inter-Retrotransposon Amplified Polymorphism) (Kalendar et al., 1999; Kalendar \& Schulman, 2006), REMAP (Retrotransposon-Microsatellite Amplified Polymorphism) (Kalendar et al., 1999; Kalendar \& Schulman, 2006), R-BIP (Retrotransposon-Based Insertional Polymorphism) (Flavell et al., 1998), TAM (Tagged Microarray Marker) (Flavell et al., 1998; Jing et al., 2007), ISBP (Insertion Site-Based Polymorphism) (Paux et al., 2010), and SSAP (Sequence-Specific Amplified Polymorphism) (Waugh et al., 1997).

We have used the SSAP approach to analyze the varieties of strawberry (Fragaria $x$ ananassa). This method is based on amplification of the DNA sequence between the conservative region of the retrotransposon (the LTR-Long Terminal Repeat sequence in our case) and the nearest restriction site for a suitable site specific restriction enzyme ( $\mathrm{Taq}^{\alpha} I$ in our case). The amplification primers are designed from the transposon conservative sequence and from a special adapter ligated to the end of the DNA cut by the restriction enzyme. The adapter is designed in such a way as to prevent adapter-to-adapter PCR amplification.

It should always be borne in mind that the polymorphism revealed by SSAP analysis is not solely determined by transposon insertion at specific sites of the genome, but may also result from SNP polymorphism at the nearest restriction site. We have performed SSAP analysis using FaRE1 retrotransposon from the Ty1-copia group. The transposon is $5104 \mathrm{bp}$ long and includes an LTR sequence $490 \mathrm{bp}$ long. Its copy number is approximately 96 per genome, which corresponds to about $0.33 \%$ of the genome (He et al., 2010).

\section{Method}

The plant material of strawberry varieties (Fragaria x ananassa) was obtained from the Russian State Agrarian University. In all, we studied 46 varieties grown in Russia.

DNA was extracted from the leaves following the technique of Torres et al. (Torres et al., 1993) with minor modifications.

SSAP analysis was carried out by the method used in the study of wheat varieties (Konovalov et al., 2010): $40 \mathrm{ng}$ of genomic DNA was treated with $10 \mathrm{U}$ of $\mathrm{Taq}^{\alpha} \mathrm{I}$ restriction enzyme for $3 \mathrm{~h}$ at $65^{\circ} \mathrm{C}$. Ligation was performed by adding 2.5 Weiss units of T4 DNA-ligase, $5 \mathrm{mM}$ ATP, and 50 pmol of double-strand adapter [5'-ACTCGATTCTCAACCCGAAAGTATAGATCCCA; 5'-PO4-CGTGGGATCTATACTT-(C6linker)-NH2] and incubation for $7 \mathrm{~h}$ at $37^{\circ} \mathrm{C}$ (Konovalov et al., 2010). The product was diluted twofold with deionized water (mQ).

The DNA sequence between the LTR region of FaRE1 retrotransposon and the Taq ${ }^{a} I$ restriction site was amplified.

The primers to the LTR region of FaRE1 retrotransposon were designed based on a sequence obtained from GenBank (accession number FJ871121) (He et al., 2010), with addition of a single selective nucleotide to reduce the number of amplified DNA fragments. The following LTR primers were used:

FaRE5: AGTAAAGATCCTAGGGACTTAACCA

FaRE3: AAAAACACAACACTAACAGTCACC

FaRE5-C: AGTAAAGATCCTAGGGACTTAACCAC

FaRE3-G: AACACAACACTAACAGTCACCG

FaRE5-G: AGTAAAGATCCTAGGGACTTAACCAG

FaRE3-C: AACACAACACTAACAGTCACCC

Amplification was performed in two stages. At the first stage only the primer to the LTR region of FaRE1 retrotransposon was used; the PCR mix contained $5 \mu \mathrm{l}$ of ligation mix, $1 \mathrm{U}$ of Taq polymerase, Taq polymerase buffer, $0.5 \mathrm{mM} \mathrm{MgCl} 2,20 \mu \mathrm{M} \mathrm{dNTP}$, and 5 pmol of LTR primer. The first amplification program was $95^{\circ} \mathrm{C}$ for $5 \mathrm{~min}$, then 30 cycles $\left(95^{\circ} \mathrm{C}\right.$ for $30 \mathrm{~s}, 6{ }^{\circ} \mathrm{C}$ for $1 \mathrm{~min}, 72^{\circ} \mathrm{C}$ for $2 \mathrm{~min}$ ), then $72^{\circ} \mathrm{C}$ for $10 \mathrm{~min}$.

At the second stage of amplification, the adapter primer 5'-GTTTACTCGATTCTCAACCCGA-3' (Konovalov et al., 2010) and one of the primers fitted to the LTR region of FaRE1 retrotransposon were used. The PCR mix contained $15 \mu \mathrm{l}$ of the first-stage PCR product, $1 \mathrm{U}$ of Taq polymerase, Taq polymerase buffer, $1.5 \mathrm{mM} \mathrm{MgCl}$, 
$200 \mu \mathrm{M}$ dNTP, $25 \mathrm{pmol}$ of LTR primer, and 25 pmol of adapter primer. The second amplification program was $95{ }^{\circ} \mathrm{C}$ for $5 \mathrm{~min}$, then 35 cycles $\left(95^{\circ} \mathrm{C}\right.$ for $30 \mathrm{~s}, 62{ }^{\circ} \mathrm{C}$ for $1 \mathrm{~min}, 72{ }^{\circ} \mathrm{C}$ for $2 \mathrm{~min}$ ), then $72{ }^{\circ} \mathrm{C}$ for $10 \mathrm{~min}$.

The PCR products were separated in denaturing polyacrylamide gel, visualized by silver staining (Bassam \& Gresshoff, 2007), and documented photographically. The presence or absence of polymorphic fragments in samples of different strawberry varieties was recorded in the form of a binary counting matrix.

The genetic distances between varieties were calculated from the binary matrix of amplified fragments using Dice's formula (Dice, 1945). The dendrogram was built with the Neighbor Joining method (Saitou \& Nei, 1987) using SplitsTree 4.10 software (Huson \& Bryant, 2006).

\section{Results}

In order to test the reproducibility of the SSAP method, we performed restriction, ligation, and amplification with FaRE5 primer twice for three strawberry varieties, after which the PCR products were visualized in polyacrylamide gel (Figure 1). As can be seen from the figure, samples from the same variety produced identical electrophoretic spectra, testifying to the reproducibility of the results obtained by this method.

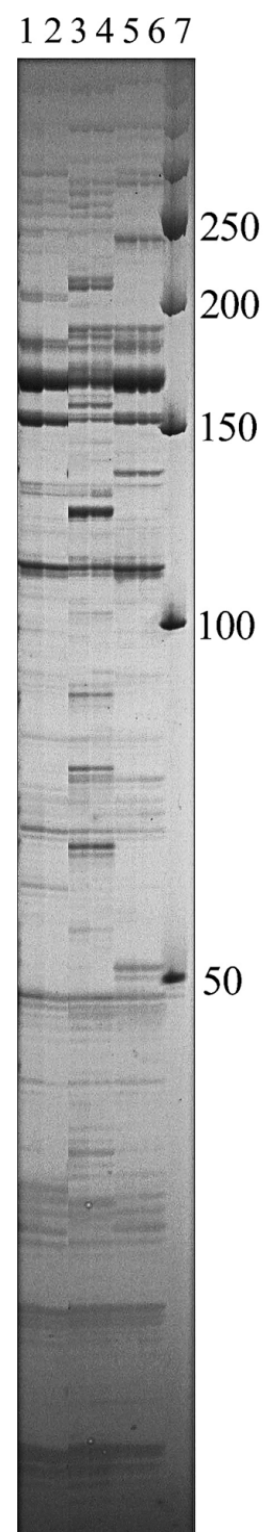

Figure 1. Test of reproducibility of SSAP markers obtained with FaRE5 primer for three strawberry varieties Lanes 1, 2: Tsarskosel'skaya; lanes 3, 4: Torpeda; lanes 5, 6: Red Gauntlet; lane 7: marker. 
We then amplified genomic DNA fragments of 11 strawberry varieties using different primers (FaRE5-C; FaRE5-G; FaRE3-G; FaRE 3-C) and analyzed the PCR products in agarose and acrylamide gels. All the procedures, starting from restriction and ligation, were run twice. The best results were obtained with FaRE5-C primer, which was therefore used in the subsequent SSAP analysis of 46 strawberry varieties.

The PCR products were separated in polyacrylamide gel, visualized by silver staining, and documented photographically (Figure 2). As can be seen from the figure, the strawberry varieties differed in the SSAP markers based on polymorphic insertions of FaRE1 retrotransposon.

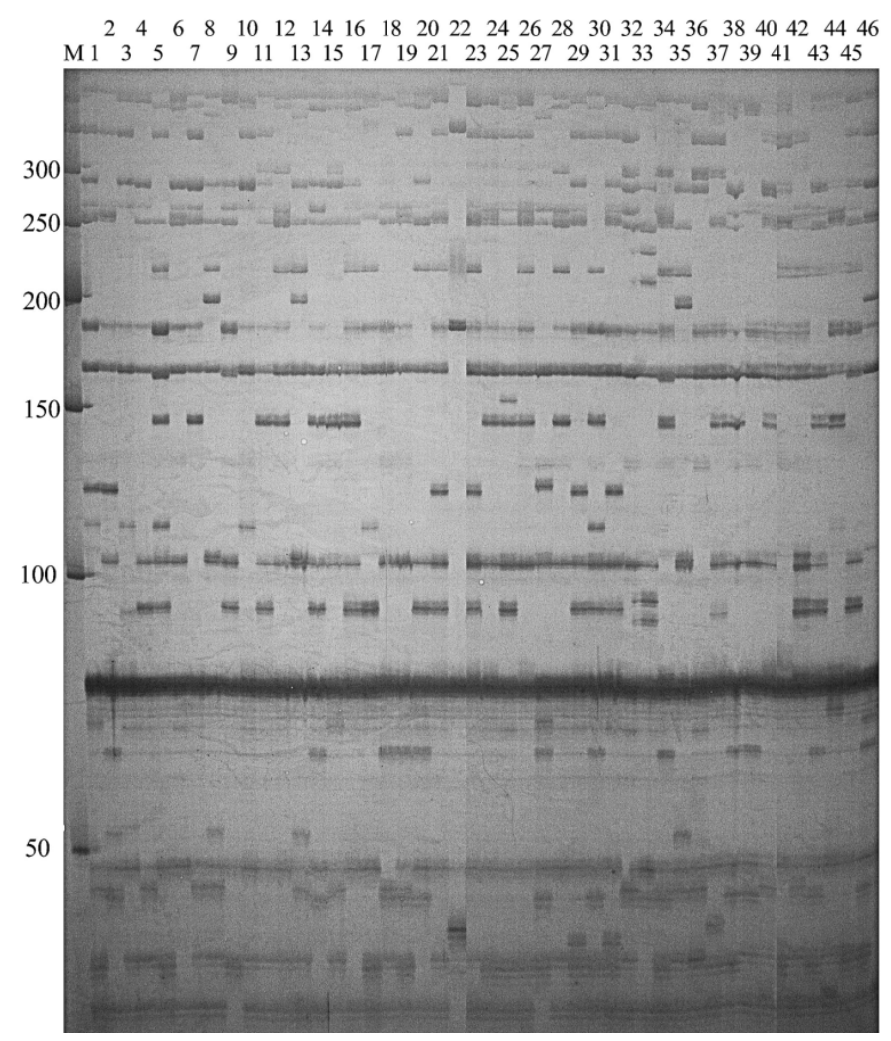

Figure 2. SSAP markers obtained with FaRE5-C primer for the following strawberry varieties

1 Mieze Schindler; 2 Vechnaya Vesna 2; 3 Holiday; 4 Estafeta; 5 Swede 2; 6 Zenit; 7 Ruslan; 8 Brighton; 9 Tribute; 10 Tsarskosel'skaya; 11 Darenka; 12 Alena; 13 Slavutich; 14 Zenga Zengana; 15 Troitskaya; 16 Firework; 17 Red Gauntlet; 18 Naidena Dobraya; 19 Vityaz; 20 Samson; 21 Carmen; 22 Melkoplodnaya; 23 Neznakomka; 24 Festival'naya Romashka; 25 Lyubava; 26 Maryshka; 27 Conrad; 28 Kubata; 29 Bereginya; 30 Krupnoplodnaya Beloplodnaya; 31 Vicoda; 32 Talka; 33 Kupchikha; 34 Kalinka; 35 Junija Smaids; 36 Zolushka; 37 Honey; 38 Symphony; 39 Corrado; 40 Queen Elizabeth; 41 Borovitskaya; 42 Tsaritsa; 43 Dukat; 44 Uralochka Rozovaya; 45 Osennyaya Zabava; 46 Zefir. M-marker.

Visual examination of the gel profiles revealed 35 polymorphic SSAP markers. Most of the studied varieties had different sets of SSAP markers but five pairs of cultivars: Alena and Kubata, Holiday and Tsarskosel'skaya, Slavutich and Junija Smaids, Ruslan and Queen Elizabeth, Bereginya and Vicoda had identical profiles.

We compiled a binary matrix of the presence/absence of polymorphic insertions of FaRE1 for 46 strawberry varieties, computed the genetic distances between them using Dice's formula (Dice, 1945), and built a dendrogram with the Neighbor Joining method (Figure 3). The dendrogram revealed no distinct clusters, i.e., the strawberry varieties could not be clearly classified into distinct groups. The 46 varieties analyzed with respect to SSAP markers were found to be quite similar genetically. A somewhat isolated position was occupied by the Kupchikha variety which is actually a hybrid of musk and strawberry. 


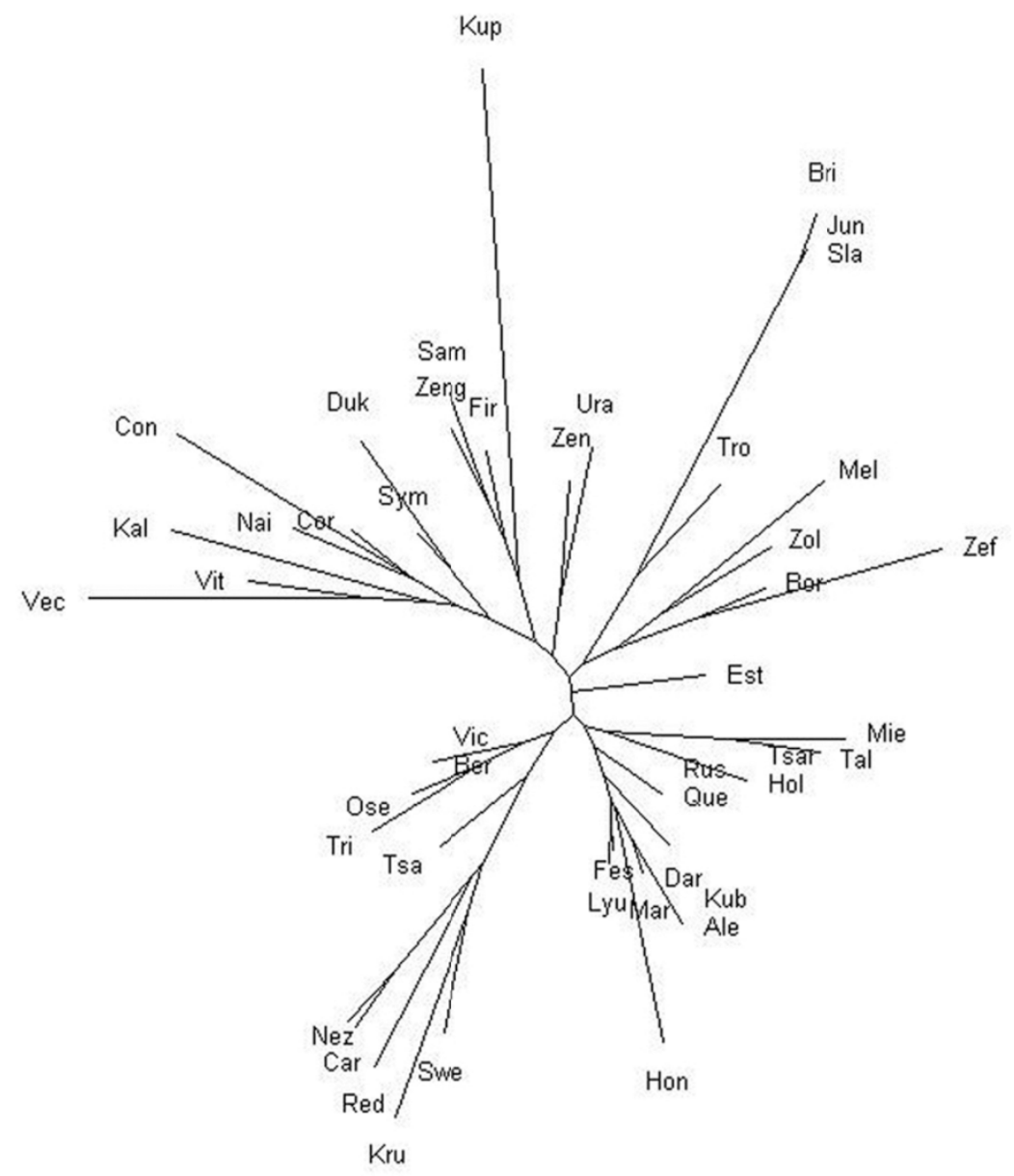

Figure 3. A Neighbor Joining dendrogram based on genetic distances (Dice indices) calculated for SSAP markers of different strawberry varieties

Alena-Ale; Bereginya-Ber; Brighton-Bri; Borovitskaya-Bor; Carmen-Car; Conrad-Con; Corrado-Cor; Darenka-Dar; Dukat-Duk; Estafeta-Est; Firework-Fir; Festival'naya Romashka-Fes; Holiday-Hol; Honey-Hon; Junija Smaids-Jun; Kalinka-Kal; Krupnoplodnaya Beloplodnaya-Kru; Kubata-Kub; Kupchikha-Kup; Lyubava-Lyu; Maryshka-Mar; Melkoplodnaya-Mel; Mieze Schindler-Mie; Naidena Dobraya-Nai; Neznakomka-Nez; Osennyaya Zabava-Ose; Queen Elizabeth-Que; Red Gauntlet-Red; Ruslan-Rus; Samson-Sam; Symphony-Sym; Slavutich-Sla; Talka-Tal; Tribute-Tri; Troitskaya-Tro; Uralochka Rozovaya-Ura; Tsaritsa-Tsa; Tsarskosel'skaya-Tsar; Swede 2-Swe; Vechnaya Vesna 2-Vec; Vicoda-Vic; Vityaz-Vit; Zenga Zengana-Zeng; Zenit-Zen; Zefir-Zef; Zolushka-Zol.

\section{Discussion}

The best results in SSAP based genotyping of $F$. x ananassa varieties were obtained using FaRE5-C primer (Figure 2). This primer was designed for the 5' end of the LTR region of FaRE1 retrotransposon and directed outward from LTR; the selective nucleotide $\mathrm{C}$ was added to the primer to reduce the number of amplified fragments. Amplification with primer FaRE5-C revealed 35 polymorphic insertions of FaRE1 retrotransposon. For comparison, during an ISSR analysis of strawberry varieties with a single primer, the total number of amplified DNA fragments varied from 7 to 16 and $85 \%$ of the markers were polymorphic (Hussein et al., 2008); in a RAPD analysis from 30 to 54 fragments per primer were amplified, $22 \%$ of them being polymorphic (Garcia et al., 2002); AFLP-PCR with 10 primers yielded 116 polymorphic markers (Tyrka et al., 2002). Microsatellite markers were successfully used to study the diversity of Fragaria (Njuguna, 2010), but in this case a pair of primers usually amplifies a single locus represented by several alleles only. Thus, SSAP reveals the greatest number of polymorphic loci in a single PCR, which makes this method promising for studying the genetic diversity of strawberry. This conclusion is confirmed by research carried out with other cultivated plants (Kalendar et al., 2011). 
Comparison of the SSAP markers obtained for strawberry showed most of its varieties (36 out of 46) to possess unique combinations of polymorphic insertions of FaRE1 retrotransposon. However, five pairs of varieties, namely Alena and Kubata, Holiday and Tsarskosel'skaya, Slavutich and Junija Smaids, Ruslan and Queen Elizabeth, Bereginya and Vicoda did not differ in the identified FaRE1 insertions. This may be accounted for by these varieties being closely related. Strawberry is a "young" crop; since varieties with the best production characteristics are commonly used as parents in breeding practice, some distinguished varieties are present in the pedigree of most cultivars. Besides, the varieties chosen for crossing are usually characterized by low genetic diversity, so that the progeny is likely to have a low level of polymorphism. The close relations among all the varieties are illustrated by the dendrogram (Figure 3) which contains no distinct genetic clusters. In our work, using a single primer to $F a R E 1$ retrotransposon, $78 \%$ of the studied varieties could be reliably identified by their SSAP markers. Our results demonstrate the possibility of using molecular markers of this kind to identify varieties in the planting stock.

FaRE1 is not the only retrotransposon found in strawberries. Other LTR retrotransposons of $F$. x ananassa (Ma et al., 2008) have been characterized; the transposon families of $F$. vesca have been identified, of which LTR retrotransposons proved to be the most abundant (Pontaroli et al., 2009; Davis et al., 2010). The sequenced genome of $F$. vesca has revealed 576 transposons (Shulaev et al., 2011), among which, according to the cited authors, LTR retrotransposons are the most abundant and comprise about $16 \%$ of the nuclear genome. The extensive data available on the strawberry transposon sequences allow the researcher to overcome one of the few drawbacks of retrotransposon-based markers, namely the need of knowing the LTR retrotransposon sequences to design the primers. The high similarity of sequences of some transposons in strawberry indicates their recent transcriptional activity (Shulaev et al., 2011); the SSAP markers based on different insertion sites of such retrotransposons may be highly polymorphic, varying even between closely related varieties. In view of the above, the SSAP technique adapted to strawberry in our work can be applied to other LTR retrotransposons identified in Fragaria. An advantage of the SSAP technique in this case is the possibility of using the same ligation mix and adaptor primer but different LTR primers, which provides a much easier way to obtain markers based on other retrotransposons. In addition, this method is theoretically capable of identifying varieties by their DNA with $100 \%$ accuracy.

\section{Acknowledgements}

The work was financially supported by Russian state grant 16.552.11.7034.

\section{References}

Bassam, B. J., \& Gresshoff, P. M. (2007). Silver staining DNA in polyacrylamide gels. Nat. Protoc., 2, 2649-2654. http://dx.doi.org/10.1038/nprot.2007.330

Bringhurst, R. S. (1990). Cytogenetics and evolution in American Fragaria. HortScience, 25, 879-881.

Davis, T. M., Shields, M. E., Zhang, Q., Tombolato-Terzić, D., Bennetzen, J. L., Pontaroli, A. C., .. Folta, K. M. (2010). An examination of targeted gene neighborhoods in strawberry. BMC Plant Biol., 10, 81. http://dx.doi.org/10.1186/1471-2229-10-81

Dice, L. R. (1945). Measures of the amount of ecologic association between species. Ecology, 26, 297-302. http://dx.doi.org/10.2307/1932409

Ellis, T. H., Poyser, S. J., Knox, M. R., Vershinin, A. V., \& Ambrose, M. J. (1998). Polymorphism of insertion sites of Ty1-copia class retrotransposons and its use for linkage and diversity analysis in pea. Mol Gen Genet, 260, 9-19. http://dx.doi.org/10.1007/PL00008630

Faedi, W., Mourges, F., \& Rosati, C. (2002). Strawberry breeding and varieties: Situation and perspectives. Acta Hort, 567, 51-59.

Feschotte, C., Jiang, N., \& Wessler, S. R. (2002). Plant transposable elements: where genetics meets genomics. Nat rev Genet, 3, 329-341. http://dx.doi.org/10.1038/nrg793

Flavell, A. J., Knox, M. R., Pearce, S. R., \& Ellis, T. H. N. (1998). Retrotransposon-based insertion polymorphisms (RBIP) for high throughput marker analysis. Plant $J, \quad 16$, 643-650. http://dx.doi.org/10.1046/j.1365-313x.1998.00334.x

Garcia, M. G., Ontivero, M., Diaz Ricci, J. C., \& Castagnaro, A. (2002). Morphological traits and high resolution RAPD markers for the identification of the main strawberry varieties cultivated in Argentina. Plant Breed, 121, 76-80. http://dx.doi.org/10.1046/j.1439-0523.2002.00671.x

Hancock, J. F. (1999). Strawberries. New York, USA, CABI Publishing. 
He, P., Ma, Y., Zhao, G., Dai, H., Li, H., Chang, L., \& Zhang, Z. (2010). FaRE1: a transcriptionally active Ty1-copia retrotransposon in strawberry. J. Plant Res., 123(5), 707-714. http://dx.doi.org/10.1007/s10265-009-0290-0

Hokanson, S. C., \& Maas, J. L. (2001). Strawberry biotechnology. Plant Breed Rev., 21, 139-180.

Huson, D. H., \& Bryant, D. (2006). Application of Phylogenetic Networks in Evolutionary Studies. Mol Biol Evol, 23(2), 254-267. http://dx.doi.org/10.1093/molbev/msj030

Hussein, T. S., Tawfik, A. A., \& Khalifa, M. A. (2008). Molecular Identification and Genetic Relationships of Six Strawberry Varieties using ISSR Markers. Int J Agri Biol, 10, 677-680.

Jing, R., Bolshakov, V., \& Flavell, A. J. (2007). The tagged microarray marker (TAM) method for high-throughput detection of single nucleotide and indel polymorphisms. Nat Protoc, 2, 168-177. http://dx.doi.org/10.1038/nprot.2006.408

Kalendar, R., \& Schulman, A. H. (2006). IRAP and REMAP for retrotransposon-based genotyping and fingerprinting. Nat Protoc, 1, 2478-2484. http://dx.doi.org/10.1038/nprot.2006.377

Kalendar, R., Flavell, A. J., Ellis, T. H. N., Sjakste, T., Moisy, C., \& Schulman, A. H. (2011). Analysis of plant diversity with retrotransposon-based molecular markers. Heredity, 106, 520-530. http://dx.doi.org/10.1038/hdy.2010.93

Kalendar, R., Grob, T., Regina, M., Suoniemi, A., \& Schulman, A. H. (1999). IRAP and REMAP: two new retrotransposon-based DNA fingerprinting techniques. Theor Appl Genet, 98, 704-711. http://dx.doi.org/10.1007/s001220051124

Konovalov, F. A., Goncharov, N. P., Goryunova, S., Shaturova, A. Proshlyakova, T., \& Kudryavtsev A. (2010). Molecular markers based on LTR retrotransposons BARE-1 and Jeli uncover different strata of evolutionary relationships in diploid wheats. Mol Genet Genomics, 283, 551-563. http://dx.doi.org/10.1007/s00438-010-0539-2

Kunihisa, M., Fukino, N., \& Matsumoto, S. (2005). CAPS markers improved by cluster-specific amplification for identification of octoploid strawberry (Fragaria $\mathrm{x}$ ananassa Duch.) cultivars, and their disomic inheritance. Theor Appl Genet, 110, 1410-1418. http://dx.doi.org/10.1007/s00122-005-1956-1

Labra, M., Imazio, S., Grassi, F., Rossoni, M., \& Sala, F. (2004). Vine-1 retrotransposon-based sequence-specific amplified polymorphism for Vitis vinifera L. genotyping. Plant Breed, 123, 180-185. http://dx.doi.org/10.1046/j.1439-0523.2003.00965.x

Lerceteau-Kohler, E., Guerin, G., Laigret, F., \& Denoyes-Rothan, B. (2003). Characterization of mixed disomic and polysomic inheritance in the octoploid strawberry (Fragaria $\times$ ananassa) using AFLP mapping. Theor Appl Genet, 107, 619-628.

Lightbourn, G. J., Jelesko, J. G., \& Veilleux, R. E. (2007). Retrotransposon-based markers from potato monoploids used in somatic hybridization. Genome, 50, 492-501. http://dx.doi.org/10.1139/G07-026

Ma, Y., Sun, H., Zhao, G., Dai, H., Gao, X., Li, H., \& Zhang, Z. (2008). Isolation and characterization of genomic retrotransposon sequences from octoploid strawberry (Fragaria $\mathrm{x}$ ananassa Duch.). Plant Cell Rep, 27, 499-507. http://dx.doi.org/10.1007/s00299-007-0476-7

Meyers, B. C., Tingey, S. V., \& Morgante, M. (2001). Abundance, distribution, and transcriptional activity of repetitive elements in the maize genome. Genome Res, 11, 1660-1676. http://dx.doi.org/10.1101/gr.188201

Njuguna, W. (2010). Development and Use of Molecular Tools in Fragaria. PhD dissertation. Oregon State.

Paux, E., Faure, S., Choulet, F., Roger, D., Gauthier, V., Martinant, J., ... Feuillet, C. (2010). Insertion site-based polymorphism markers open new perspectives for genome saturation and marker-assisted selection in wheat. Plant Biotechnology J, 8, 196-210. http://dx.doi.org/10.1111/j.1467-7652.2009.00477.x

Pearce, S. R., Harrison, G., Li, D., Heslop-Harrison, J. S., Kumar, A., \& Flavell, A. J. (1996). The Tyl-copia group of retrotransposons in Vicia species: copy number, sequence heterogeneity and chromosomal localisation. Mol Gen Genet, 205, 305-315. http://dx.doi.org/10.1007/BF02174388

Pearce, S. R., Knox, M., Ellis, T. H., Flavell, A. J., \& Kumar, A. (2000). Pea Ty1-copia group retrotransposons: transpositional activity and use as markers to study genetic diversity in Pisum. Mol Gen Genet, 263, 898-907. http://dx.doi.org/10.1007/s004380000257 
Pontaroli, A. C., Rogers, R. L., Zhang, Q., Shields, M. E., Davis, T. M., Folta, K. M., ... Bennetzen, J. L. (2009). Gene content and distribution in the nuclear genome of Fragaria vesca. Plant Genome, 2, 93-101. http://dx.doi.org/10.3835/plantgenome2008.09.0007

Queen, R. A., Gribbon, B. M., James, C., Jack, P., \& Flavell, A. J. (2004). Retrotransposon-based molecular markers for linkage and genetic diversity analysis in wheat. Mol Genet Genomics, 271, 91-97. http://dx.doi.org/10.1007/s00438-003-0960-x

Saito, N., \& Nei, M. (1987). The neighbor-joining method: a new method for reconstructing phylogenetic trees. Mol Biol Evol, 4, 406-425.

SanMiguel, P., \& Bennetzen, J. L. (1998). Evidence that a recent increase in maize genome size was caused by the massive amplification of intergene retrotransposons. Ann. Bot., 81, 37-44. http://dx.doi.org/10.1006/anbo.1998.0746

Sanz, A. M., Gonzalez, S. G., Syed, N. H., Suso, M. J., Saldana, C. C., \& Flavell, A. J. (2007). Genetic diversity analysis in Vicia species using retrotransposon-based SSAP markers. Mol Genet Genomics, 278, 433-441. http://dx.doi.org/10.1007/s00438-007-0261-x

Shulaev, V., Sargent, D. J., Crowhurst R. N., Mockler T. C., Folkerst O., Delcher A. L., .. Celton J. M. (2011). The genome of woodland strawberry (Fragaria vesca). Nat Genet, 43, 109-116. http://dx.doi.org/10.1038/ng.740

Smykal, P., Bacova-Kerteszova, N., Kalendar, R., Corander, J., Schulman, \& A. H., Pavelek, M. (2011). Genetic diversity of cultivated flax (Linum usitatissimum L.) germplasm assessed by retrotransposon-based markers. Theor Appl Genet, 122, 1385-1397. http://dx.doi.org/10.1007/s00122-011-1539-2

Tang, T., Huang, J., Zhong, Y., \& Shi, S. (2004). High-throughput S-SAP by fluorescent multiplex PCR and $\begin{array}{lllll}\text { capillary electrophoresis in plants. J. Biotechnol, } & 114, & \text { 59-68. }\end{array}$ http://dx.doi.org/10.1016/j.jbiotec.2004.06.001

Torres, A. M., Weeden, N. F., \& Martin, A. (1993). Linkage among isozyme, RFLP and RAPD markers in Vicia faba. Theor Appl Genet, 85, 937-945. http://dx.doi.org/10.1007/BF00215032

Tyrka, M., Dziadczyk, P., \& Hortynski, J. A. (2002). Simplified AFLP procedure as a tool for identification of strawberry cultivars and advanced breeding lines. Euphytica, 125, 273-280. http://dx.doi.org/10.1023/A:1015892313900

Vershinin, A. V., Allnutt, T. R., Knox, M. R., Ambrose, M. J., \& Ellis, T. H. (2003). Transposable elements reveal the impact of introgression, rather than transposition, in Pisum diversity, evolution, and domestication. Mol Biol Evol, 20, 2067-2075. http://dx.doi.org/10.1093/molbev/msg220

Vilanova, S., Arus, P., Sargent, D. J., \& Monfort, A. (2008). Synteny conservation between two distantly-related Rosaceae genomes: Prunus (the stone fruits) and Fragaria (the strawberry). BMC Plant Biology, 8, 67. http://dx.doi.org/10.1186/1471-2229-8-67

Waugh, R., McLean, K., Flavell, A. J., Pearce, S. R., Kumar, A., Thomas, B. B., \& Powell, W. (1997). Genetic distribution of Bare-1-like retrotransposable elements in the barley genome revealed by sequence-specific amplification polymorphisms (S-SAP). Mol Gen Genet, 253(6), 687-694. http://dx.doi.org/10.1007/s004380050372

Wicker, T., Taudien, S., Houben, A., Keller, B., Graner, A., Platzer, M., \& Stein, N. (2009). A whole-genome snapshot of 454 sequences exposes the composition of the barley genome and provides evidence for parallel evolution of genome size in wheat and barley. Plant $J, 59(5), \quad 712-22$. http://dx.doi.org/10.1111/j.1365-313X.2009.03911.x 